\title{
Elaboração de bolo com farinha de Yacon
}

\author{
Cake developed with Yacon flour \\ Claudia Severo da Rosa ${ }^{\mathrm{I}}$ Viviani Ruffo de Oliveira ${ }^{\mathrm{II}}$ Vanessa Bordin Viera ${ }^{\mathrm{II}}$ \\ Camila Gressler ${ }^{\text {II }}$ Suelem Viega ${ }^{\text {II }}$
}

\section{RESUMO}

\begin{abstract}
A batata yacon apresenta carboidratos na forma de frutooligossacarídeos (FOS). Estudos comprovam que os FOS aumentam a saciedade e reduzem o índice glicêmico. Os produtos da fermentação podem minimizar a resposta glicêmica, além de estimular a glicólise, e ainda resultam em uma porção reduzida de energia. Os objetivos deste trabalho foram elaborar a farinha de yacon, avaliar a composição química de diferentes concentrações de farinha de yacon na elaboração de bolos e analisar sensorialmente as preparações elaboradas. A farinha de yacon apresentou potencial como ingrediente na formulação de bolos, uma vez que teve boa aceitabilidade
\end{abstract}

Palavras-chave: yacon, bolo, FOS.

\section{ABSTRACT}

The yacon potatoes present carbohydrates in the form of fructo oligosaccharides (FOS). There are studies proving that the FOS delays the gastric emptying, increase the alimentary fiber,have prebiotic and hypoglycemic effects. They stimulate glycolysis, resulting in a reduced amount of energy. The objective of this research was to evaluate the chemical composition of cakes formulated with different concentrations of Yacon flour and to evaluate their sensory characteristics. The Yacon flour presented potential to be a cake ingredient.

Key words: yacon, cake, FOS.

\section{INTRODUÇÃO}

A yacon foi introduzida no Brasil, no início dos anos 90 (MOSCATTO et al., 2004). Em meados dos anos 2000, teve início o consumo expressivo dessa raiz, e ela tornou-se conhecida popularmente como batata yacon ou batata “diet” (SANTANA \& CARDOSO, 2008). A planta yacon é um tubérculo que apresenta características particulares: tem um agradável sabor doce e, devido ao seu alto conteúdo aquoso, deixa a sensação refrescante depois de ser consumida, razão pela qual é considerada como uma fruta (MALDONADO et al., 2008).

Na sua composição, a batata yacon tem como principais substâncias água e carboidratos, os quais são armazenados principalmente sob forma de frutooligossacarídeos (FOS), dentre outros açúcares livres (SANTANA \& CARDOSO, 2008). O valor energético da raiz é considerado baixo devido ao alto conteúdo de água que se situa em torno de 83 e 90\% do peso fresco (LACHMAN et al., 2004).

As raízes contêm entre 10 e $14 \%$ de matéria seca, sendo esta composta por aproximadamente $90 \%$ de carboidratos (MANRIQUE \& PÁRRAGA, 2005). Dentre os açúcares encontrados, estão os monossacarídeos frutose e glicose, dissacarídeo sacarose e os FOS, além de traços de amido e inulina (GRAU \& REA, 1997).

O percentual de FOS encontrado na batata yacon situa-se em torno de 40 e $70 \%$ dos carboidratos, os quais são também chamados de açúcares não convencionais com grande impacto na indústria do

ICentro Universitário Franciscano (UNIFRA), 97010-033, Santa Maria, RS, Brasil. Email: claudiasr37@yahoo.com.br. Autor para correspondência.

"Curso de Nutrição, UNIFRA, Santa Maria, RS, Brasil. 
açúcar em razão das suas excelentes características funcionais em alimentos, além de seus aspectos fisiológicos e físicos (SPIEGEL et al., 1994).

Os FOS apresentam cerca de um terço do poder adoçante da sacarose e são pouco calóricos. Têm solubilidade maior que à da sacarose, não cristalizam, não precipitam e nem deixam sensação de areia ou secura na boca. Eles não são degradados durante a maioria dos processos de aquecimento, mas podem ser hidrolisados em frutose, em condições muito ácidas e em exposição prolongadas ao binômio tempo/ temperatura (BORNET, 1994; YUN, 1996).

Os produtos da fermentação podem minimizar as respostas glicêmica e insulinêmica pósprandiais, além de estimular a glicólise, e ainda resultar em uma porção reduzida de energia. MAYTA et al. (2004) realizaram um estudo experimental, com seis indivíduos adultos sadios, e detectaram que a raiz fresca do yacon diminuiu em 79,8\% a resposta glicêmica dos sujeitos durante o Teste de Tolerância Oral da Glicose (TTOG), evitando o pico de glicose pós-prandial.

O setor alimentício está envolto em um ambiente altamente dinâmico regido por constantes mudanças dos padrões de consumo. A crescente exigência do consumidor por alimentos que apresentem, além de alta qualidade sensorial e nutricional, benefícios associados à saúde, faz surgir a necessidade de novos ingredientes e produtos que possam atender a essas exigências do mercado.

Este trabalho teve como objetivos elaborar a farinha de yacon, avaliar a composição química de diferentes concentrações de farinha de yacon na elaboração de bolos e analisar sensorialmente essas preparações elaboradas.

\section{MATERIAL E MÉTODOS}

Elaboração da farinha

A farinha de yacon foi obtida a partir de raízes tuberosas de yacon, sendo descascadas manualmente e imersas por 10 min em solução de metabissulfito de sódio. A desidratação a $60^{\circ} \mathrm{C}$ foi feita em estufa De Leo, com circulação de ar por 48 horas. $\mathrm{O}$ material desidratado foi triturado em processador, baseado na metodologia usada por BORBA et al. (2005); GIOVANNA\& PALOMINO (2004).
A elaboração dos produtos foi realizada no Laboratório de Técnica Dietética no Centro Universitário Franciscano - UNIFRA, e as análises químicas foram realizadas no Laboratório de Bromatologia da mesma instituição.

\section{Elaboração dos bolos}

As preparações foram elaboradas de acordo com receitas pré-testadas, seguindo as técnicas de elaboração descritas a seguir:

Bolo Padrão: A massa do bolo misturada em batedeira doméstica continha três gemas, farinha de trigo (250g), edulcorante (frutose) (80g), água morna (130mL), leite integral (130mL). A essa mistura, foram adicionadas três claras batidas em neve, as quais foram misturadas manualmente com $20 \mathrm{~g}$ de fermento em pó. A massa foi acondicionada em forma de alumínio retangular, previamente untada com margarina e polvilhada com farinha de trigo, levada ao forno convencional pré-aquecido por 15 minutos a $220^{\circ} \mathrm{C}$ e assada por 45 minutos.

Bolo com Yacon 10,00\%: A massa do bolo diferiu somente na quantidade de farinha de trigo (225g) e no acréscimo da farinha de yacon (25g).

Bolo com Yacon 20,00\%: A massa do bolo diferiu somente na quantidade de farinha de trigo (200g) e no acréscimo de farinha de yacon (50g).

\section{Composição química dos bolos}

As análises de composição química foram realizadas em triplicata, segundo as metodologias descritas pela Association Of Official Analytical Chemists (AOAC, 1995).

\section{Análise sensorial}

Para o teste de preferência dos bolos, foi utilizado o teste de escala hedônica de 9 pontos (9 = gostei muitíssimo; 5 = nem gostei nem desgostei e 1 = desgostei muitíssimo) para avaliar os atributos cor, aroma, aspecto, textura e sabor. Participaram do teste 35 provadores, de ambos os sexos e com idade entre 20 e 55 anos, os quais receberam as amostras codificadas com três dígitos aleatórios e em ordem casualizada (TEIXEIRA et al., 1987).

Ciência Rural, v.39, n.6, set, 2009. 
Análise estatística

O delineamento utilizado foi o inteiramente casualizado, com três repetições, e os resultados obtidos foram avaliados por meio da análise de variância (ANOVA). Foi aplicado o teste de Tukey, a $5 \%$ de probabilidade do erro, para a comparação das médias entre as amostras. As análises estatísticas foram realizadas por meio do programa ESTAT, versão 2.0.

\section{RESULTADOS E DISCUSSÕES}

Composição química dos bolos

O bolo elaborado com 10\% de yacon (Tabela 1) apresentou maior umidade do que as duas outras formulações avaliadas. Os FOS, devido a sua constituição química, possuem grupos $\mathrm{OH}$ disponíveis para ligação e são capazes de interagir com a água, por ligações de hidrogênio, dificultando sua evaporação durante o processo de assadura do bolo (ROBERFROID, 1993; SILVA, 1996). Resultado semelhante foi encontrado por BURITI (2005), o qual, ao adicionar maior quantidade de inulina na elaboração de queijos cremosos, obteve aumento no teor de sólidos e redução no teor de umidade.

O conteúdo de cinzas foi maior no bolo elaborado com $20 \%$, seguido pelo bolo elaborado a $10 \%$ e pelo bolo padrão. Esse resultado está em concordância com um estudo realizado por MOSCATTO et al. (2004), os quais, ao substituirem $20 \%$ da farinha de trigo pela farinha de yacon, encontraram um valor superior $(1,67 \%)$ ao encontrado no bolo padrão (1,42\%).

Todavia, o teor de lipídios e proteína foi mais expressivos no bolo padrão, seguido do bolo com $10 \%$ e $20 \%$, respectivamente. Os resultados encontrados neste estudo também corroboram os resultados do estudo de SILVA (1996). A principal exigência para a formação de massa adequada, dependendo do tipo de bolo, é que a mistura tenha quantidade suficiente de proteínas, para que, durante o forneamento, a estrutura protéica formada possa se espalhar sobre os componentes da farinha (MORR et al., 2003). Caso contrário, a fraca estrutura protéica diminuirá a retenção de gás na massa e favorecerá a formação de estrutura compacta e de baixo volume.

Durante a mistura dos ingredientes, as proteínas absorvem quantidade considerável de água e interagem para a formação da rede de glúten. De acordo com a composição físico-química apresentada pela farinha, ocorre nessa etapa a formação de sistema coloidal, o qual envolve lipídios, açúcares, minerais e proteínas, dentre outros (GUTKOSKI \& NETO, 2002).

Análise sensorial dos bolos

Os resultados obtidos para cada atributo sensorial dos bolos estão apresentados na tabela 2 . Os atributos cor, sabor e textura apresentaram diferenças estatísticas $(\mathrm{P}<0,05)$. O bolo formulado com 20,00\% de farinha de yacon apresentou-se mais firme e com maior resistência ao corte. A avaliação sensorial do atributo aparência não evidenciou diferença estatística significativa entre os três bolos. Sendo a aparência o primeiro fator a ser levado em consideração quando se avalia um alimento, isso pode indicar que o bolo com farinha de yacon pode alcançar a aceitação inicial do consumidor.

\section{CONCLUSÕES}

A farinha de yacon apresentou potencial para participar como ingrediente em formulação de bolos, pois as formulações que continham farinha de yacon apresentaram características sensoriais agradáveis.

Tabela 1 - Composição química de bolos com e sem adição de yacon* .

\begin{tabular}{lcccccccc}
\hline Tratamentos & Umidade $\%$ & DP & Cinzas \% & DP & Lipídios \% & DP & Proteína \% & DP \\
\hline Bolo padrão & $35,48^{\mathrm{b}}$ & 0,235 & $1,99^{\mathrm{c}}$ & 0,006 & $8,40^{\mathrm{a}}$ & 0,197 & $7,78^{\mathrm{a}}$ & 0,095 \\
Bolo 10\% & $37,66^{\mathrm{a}}$ & 0,206 & $2,10^{\mathrm{b}}$ & 0,021 & $7,47^{\mathrm{b}}$ & 0,114 & $7,09^{\mathrm{b}}$ & 0,025 \\
Bolo 20\% & $35,17^{\mathrm{b}}$ & 0,045 & $2,20^{\mathrm{a}}$ & 0,023 & $7,07^{\mathrm{c}}$ & 0,059 & $6,22^{\mathrm{c}}$ & 0,087 \\
\hline
\end{tabular}

*Médias com letras iguais, na mesma coluna, não diferem entre si estatisticamente $(\mathrm{P}>0,05)$.

Ciência Rural, v.39, n.6, set, 2009. 
Tabela 2 - Análise sensorial de bolos com e sem adição de farinha de yacon $^{*}$.

\begin{tabular}{llccc}
\hline Tratamentos & Cor & Sabor & Aparência & Textura \\
\hline bolo padrão & $5,60^{\mathrm{a}}$ & $5,11^{\mathrm{ab}}$ & $5,51^{\mathrm{a}}$ & $5,94^{\mathrm{ab}}$ \\
bolo $10 \%$ & $4,77^{\mathrm{b}}$ & $4,71^{\mathrm{b}}$ & $4,77^{\mathrm{a}}$ & $5,34^{\mathrm{b}}$ \\
bolo 20\% & $4,91^{\mathrm{ab}}$ & $5,48^{\mathrm{a}}$ & $5,11^{\mathrm{a}}$ & $6,05^{\mathrm{a}}$ \\
\hline
\end{tabular}

*Médias com letras iguais, na mesma coluna, não diferem entre si estatisticamente $(\mathrm{P}>0,05)$.

\section{REFERÊNCIAS}

ASSOCIATION OF OFFICIAL ANALYTICAL CHEMISTS (AOAC). Official Methods of Analysis of the Association of Official Analytical Chemists. 16.ed. Arlington, 1995. 1018p.

BORBA, A.M. et al. Efeitos dos parâmetros de extrusão sobre as propriedades funcionais de extrusados da farinha de batatadoce. Ciência e Tecnologia de Alimentos, v.25, n.4, p.835843, 2005.

BORNET, F.R. Undigestible sugars in food products. American Journal of Clinical Nutrition, v.59, n.3, Suppl, p.763-769, 1994.

BURITI, F.C.A. Desenvolvimento de queijo fresco cremoso simbiótico. 2005. 86f. Dissertação (Mestrado em Tecnologia Bioquímico-Farmacêutica) - Universidade de São Paulo, São Paulo.

GIOVANNA, R.; PALOMINO, Q. Obtención y caracterizacion fisicoquímica del harina de yacon. Huancayo-Perú: Facultad de Ingeniería en Industrias Alimentarias, UNCP, 2004. $19 \mathrm{f}$.

GRAU, A; REA, J. Yacon. Smallanthus sonchifolius (Poep. \& Endl.) H. Robinson. In: HERMANN, M.; HELLER, J. (Eds.). Andean roots and tubers: ahipa, arracacha, maca and yacon. Promoting the conservation and use of underutilized and neglected crops. (Institute of Plant Genetics and Crop Plant Research). Rome, Italy: Gatersieben/ International Plant Genetic Resources Institute. 1997. p.199242. Disponível em: <http://www.cipotato.org/market/ ARTChermann/yacon.pdf>. Acesso: 4 agost. 2008.

GUTKOSKI, L.C.; NETO, R.J. Procedimento para teste laboratorial e panificação: pão tipo forma. Ciência Rural, v.32, p.873-879, 2002.

MALDONADO, S. et al. Cinética de la transferencia de masa durante la deshidratación osmótica de yacón (Smallanthus sonchifolius). Ciência e Tecnologia de Alimentos, Campinas, v.28, n.1, 2008. Diponível em: < http://www.scielo.br/ s c i e l o.p h p ? s c r i p t = s c i_a r t t ex t \& p i d = S 0 $10120612008000100036 \& \operatorname{lng}=\mathrm{es} \& \mathrm{nrm}=\mathrm{is} \& \operatorname{lng}=\mathrm{es}>$. Acesso em: 06 Sep. 2008. Doi: 10.1590/S0101-20612008000100036.

MANRIQUE, I.; PÁRRAGA, A. Conservación y uso de la biodiversidad de raíces y tubérculos Andinos: Una década de investigación para el desarrollo (1993-2003). Jarabe de yacón: principios y procesamiento. Lima: Centro Internacional de La Papa, 2005. 40p.

MAYTA, P. et al. Reducción de la respuesta glicémica posprandial post-ingesta de raíz fresca de yacon en sujetos sanos. CIMEL, v.9, n.1, p.9-11, 2004.

MORR, C.V. et al. Use of applied air pressure to improve the baking properties of whey protein isolates in angel food cakes. Lebensmittell-Wissenschaft und- Technologie, v.36, n.1, p.83-90, 2003. Disponível em:< http://www.sciencedirect.com/ science?_ob=ArticleURL\&_udi=B6WMV-47VYK3H$1 \&$ _user $=10$ \&_rdoc $=1 \&$ fmt $=$ \&_orig $=$ search\&_sort $=\mathrm{d} \&$ view $=\mathrm{C}$

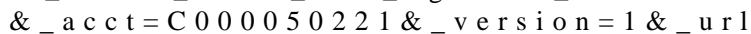
Version=0\&_userid=10\&md5=67b5249abcdf1de6297e69621ed228d0 $>$. Acesso em: 16 abr. 2009. Doi: 10.1016/S0023-6438(02)00187-1.

MOSCATTO, J.A. et al. Farinha de yacon e inulina como ingredientes na formulação de bolo de chocolate. Ciência e Tecnolologia de Alimentos, Campinas, v.24, n.4, p.634-640, 2004.

ROBERFROID, M.B. Dietary fiber, inulin and oligofructose: a review comparing their physiological effects. CRC-Critical Reviews Food Science and Nutrition, v.33, n.2, p.103148, 1993.

SANTANA, I.; CARDOSO, M.H. Raiz tuberosa de yacon (Smallanthus sonchifolius): potencialidade de cultivo, aspectos tecnológicos e nutricionais. Ciência Rural, v.38, n.3. p.898905, 2008. Disponível em: <http://www.scielo.br/ s c i e l o.ph p ? s c ri p t = s c i_a r t t ex t \& pi d = S 010 $384782008000300050 \& \operatorname{lng}=\mathrm{e} \& \mathrm{nrm}=\mathrm{iso}>$. Acesso em: 06 set. 2008. Doi: 10.1590/S0103-84782008000300050.

SILVA, R.F. Use of inulin as a natural texture modifier. Cereal Foods World, v.41, n.10, p.792-794, 1996.

SPIEGEL, J.E. et al. Safety and benefits of frutooligosaccharides as food ingredients. Food Techn, v.48, p.85-89, 1994.

TEIXEIRA, E. et al. Métodos sensoriais. In: UFSC (Ed). Análise sensorial de alimentos. Florianópolis: UFSC, 1987. p.66-119.

YUN, J.W. Fructooligosaccharides: occurrence, preparation and applications. Enzymes and Microbial Technology, v.19, n.2, p.107-117,1996. 